\title{
Towards high resolution ceramic series for production site studies: the case of Loron amphorae (Croatia, 1st-3rd c. A.D.)
}

\author{
Pierre Machut ${ }^{1{ }^{*}+}$, Ayed Ben Amara $^{1 \dagger}$, Nadia Cantin ${ }^{1 \dagger}$, Rémy Chapoulie $^{1 \dagger}$, Nicolas Frèrebeau $^{1 \dagger}$, \\ François-Xavier Le Bourdonnec ${ }^{1 \dagger}$, Yolande Marion $^{2+}$ and Francis Tassaux ${ }^{2+}$
}

\begin{abstract}
Background: From the 1st to the 3rd centuries A.D., the territory of Istria (present-day Croatia) was a prominent area of olive oil production. Archaeologists have identified the so-called Dressel 6B amphora as the main container used in the transport and trade of this oil. So far archaeology and epigraphy have helped identify probable sources of production and two workshops in Istria, and have also allowed the reconstruction of main trade routes through the identification of stamped amphorae. However, much less is known about the organization of the production of these ceramic containers, which may have been conducted on an almost industrial scale. This preliminary study demonstrates how chemical analysis using energy-dispersive X-ray fluorescence spectrometry (EDXRF) may address this question and provide new answers and avenues of inquiry.
\end{abstract}

Results: Our study of 53 amphorae, produced during two important periods in the history of the workshop of Loron, has evidenced that even in chronologically closely related contexts of production chemical analysis could significantly separate samples according to production groups.

Conclusions: This result constitutes a very important first step towards a thorough study of the entire production history of the workshop, involving the creation of a comprehensive geochemical reference group comprising several hundred samples. This in turn will enable us to address an array of hypotheses concerning the economy and ecology of this production site, which are briefly presented in the article. The application of this methodology to the whole corpus of Istrian amphorae is then advocated in light of this study.

\section{Background}

Within the field of ceramic characterization, comprehensive studies of workshop production sites usually require considerable analytical work, which exceeds by far the scope of most archaeological science research projects. Pollard and Heron pointed out the implications of this issue in 1996: "most kiln sources are characterized by at best a hundred analyses, probably covering a range of "qualities" of vessels produced, a range of vessel types, and, possibly, a time span of tens or even hundreds of years.

*Correspondence: pierre.machut@u-bordeaux-montaigne.fr

${ }^{\dagger}$ All authors contributed equally to this work

${ }^{1}$ IRAMAT-CRP2A, UMR 5060 CNRS, Université Bordeaux Montaigne,

Pessac, France

Full list of author information is available at the end of the article
Essentially the archaeological chemist is relying on the quality control procedures in force in antiquity to ensure that the sample is representative of the range of compositions produced!" [1]. Any study aiming to precisely assess the range of compositions produced in a specific location should thus address this question of representativeness first and foremost. Sample selection is a crucial step in this regard, and appropriate sampling should include a suitable number of samples of each vessel type for every production group recorded at a workshop site. Consequently, hundreds of samples potentially need to be processed in order to answer even the simplest archaeological questions with minimal confidence. Although such highresolution studies are-for obvious reasons-scarce, we advocate that attempting to apply it to an appropriate case study would yield significant results.

\section{Chemistry Central}

(c) 2015 Machut et al. This article is distributed under the terms of the Creative Commons Attribution 4.0 International License (http://creativecommons.org/licenses/by/4.0/), which permits unrestricted use, distribution, and reproduction in any medium, provided you give appropriate credit to the original author(s) and the source, provide a link to the Creative Commons license, and indicate if changes were made. The Creative Commons Public Domain Dedication waiver (http://creativecommons.org/ publicdomain/zero/1.0/) applies to the data made available in this article, unless otherwise stated. 
In order to demonstrate this assumption, we chose two well-defined production groups-according to archaeological criteria-from the Loron amphora workshop site, dating from the Roman era. Subsequently, we applied quantitative chemical analysis by energy-dispersive $\mathrm{x}$-ray fluorescence spectrometry (EDXRF) and statistical data treatment on a significant number of those samples.

From the 1st to the 3rd centuries A.D., the territory of Istria (present-day Croatia) was a prominent area of olive oil production. This oil of great repute was exported in the so-called Dressel 6B (Dr 6B) amphorae towards northern Italy and the Danubian provinces, along major trade roads in the Empire (Figure 1). Production during the 1 st century was dominated by the workshops of Fažana in the southern part of the peninsula, on the territory of Pola (modern-day Pula), and Loron, on the territory of Parentium (modern-day Poreč) (Figure 2). Initially, they were private properties controlled by aristocratic families, but then both workshops became part of the imperial domain under the Flavians. At Loron, the history of ownership is well documented through extensive stamping of the ceramic containers.

Two decades of intensive research have resulted in a precise picture of the ceramic categories produced at Loron and of the trade circuits of Dr 6B amphorae [2]. However, archaeological and epigraphic investigations fail to answer precise questions about the actual production process established in the workshop. Despite much speculation about the organization of production a lot

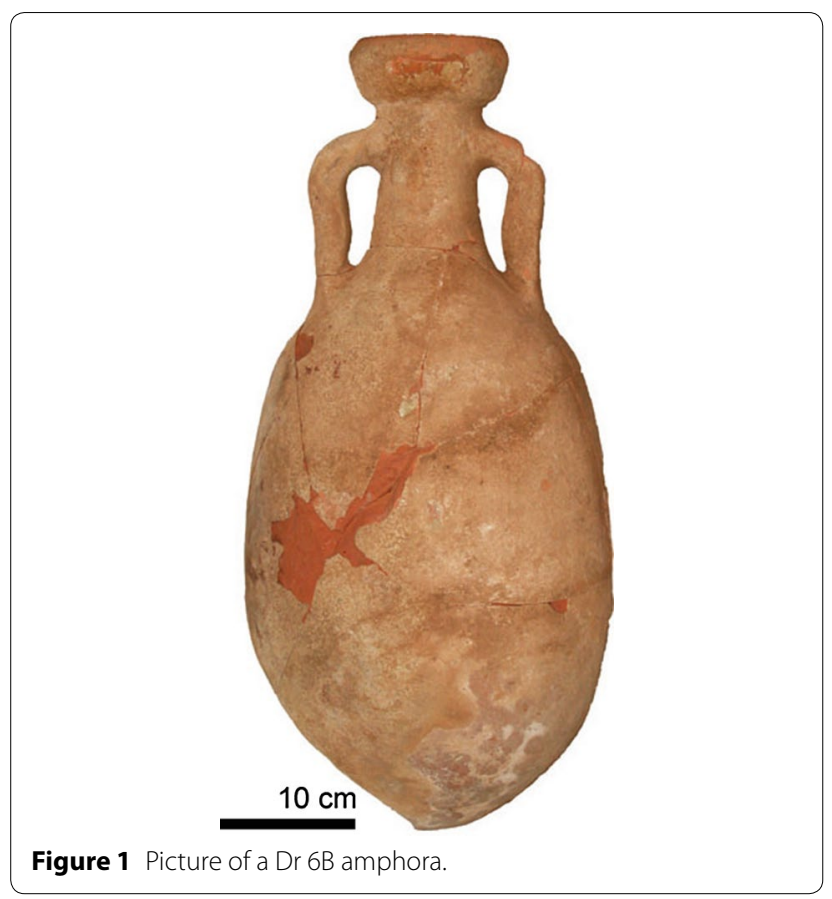

of questions remain, since only two workshops at Loron and Fažana have been located and partially excavated. Moreover, our knowledge of epigraphic sources is limited to only a few examples in the case of some lesserknown stamps while most of the ceramic material is still untapped due to lack of inscriptions.

When dealing with such large structures, the output of which would have been enormous for preindustrial times, the aspects of technology and standardisation must also be considered in order to address the actual questions of historical significance. Namely, understanding the inner workings of Roman economy through the specific case of olive oil trade.

The two production groups chosen for this study are separated in time by a gap of at most 50 years. Each one corresponds to an important step in the history of the workshop: the productions of Sisenna, founder and first owner of the site, and Domitian, first owner of imperial status. The owners are clearly identified by the amphora stamps bearing their names. Dating of each production group comes mainly from the identification of these characters in other sources such as epigraphy.

EDXRF was chosen for its versatility and ubiquity in archaeological ceramic paste composition studies, for which its potential has been demonstrated many times. Any attempt to highlight patterns in a dataset for such a restricted scale (locally and chronologically) needs to make use of robust data analysis methods; thus our results were submitted to exploratory statistical analysis.

\section{Results}

Quantitative results were obtained for 9 major, minor and trace elements measured by EDXRF in all 53 samples (cf. "Methods" below). Elemental composition ranges for both production groups are reported in Table 1. Several observations can be made at once from a cursory examination of the results. Firstly, ceramic pastes are calcareous, with a mean of $14.01 \mathrm{wt}$ \% $\mathrm{CaO}$ in the case of Sisenna and 10.41 wt.\% $\mathrm{CaO}$ in the case of Domitian. Moreover, the iron content is significant, with values higher than 6 wt.\%. Low relative standard deviations show that each group is internally quite homogeneous.

Both individuals and variables scatterplots of the results of principal component analysis are displayed in Figures 3, 4. The first two components, accounting for almost $87 \%$ of explained variation, show a clear tendency for values to plot according to production group origin, even though clustering is not optimal at this point.

This exploratory approach already provides us with a promising result, since patterns readily emerge. In order to improve this result and achieve better grouping, discriminating elements were chosen from the variables 


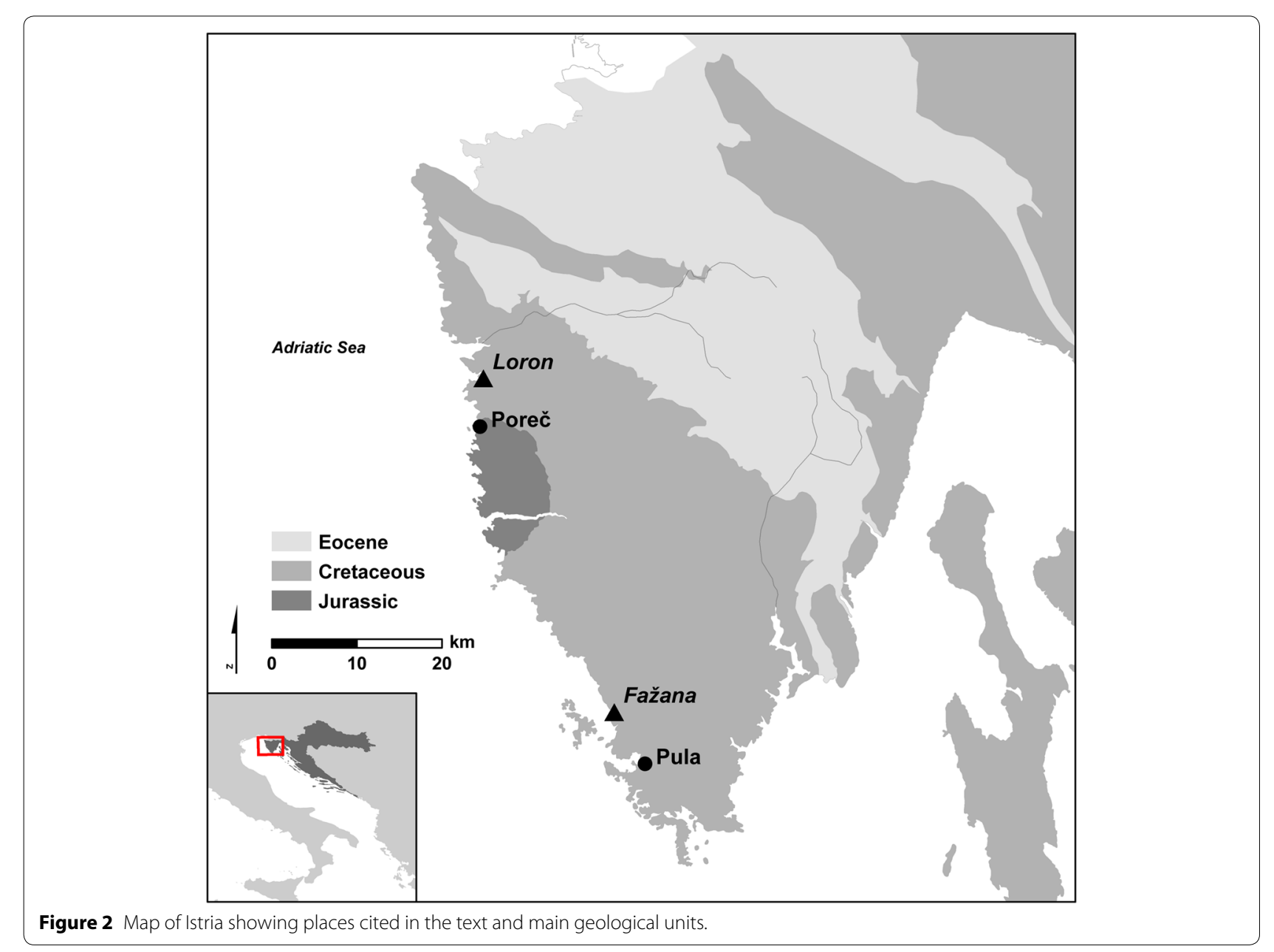

Table 1 Composition ranges for Sisenna and Domitian production groups

\begin{tabular}{lrrrrrrrrr}
\hline & $\mathbf{A l}_{\mathbf{2}} \mathbf{O}_{\mathbf{3}}$ & $\mathbf{S i O}_{\mathbf{2}}$ & $\mathbf{K}_{\mathbf{2}} \mathbf{O}$ & $\mathbf{C a O}$ & $\mathbf{T i O}_{\mathbf{2}}$ & $\mathrm{Fe}_{\mathbf{2}} \mathbf{O}_{\mathbf{3}}$ & $\mathbf{R b}$ & $\mathbf{S r}$ & $\mathbf{Z r}$ \\
\hline Average Sisenna & 14.25 & 56.12 & 1.77 & 14.01 & 0.83 & 6.01 & 119 & 278 & 156 \\
St. dev. & 0.52 & 1.40 & 0.10 & 2.07 & 0.04 & 0.29 & 12 & 26 & 11 \\
\%St. dev. & 3.66 & 2.49 & 5.65 & 14.74 & 4.65 & 4.78 & 10 & 9 \\
Average Domitian & 14.83 & 57.56 & 2.21 & 10.41 & 0.88 & 6.38 & 138 & 220 & 153 \\
St. dev. & 0.36 & 1.18 & 0.08 & 1.13 & 0.05 & 0.27 & 12 & 14 & 10 \\
\%St. dev. & 2.44 & 2.06 & 3.63 & 10.89 & 6.02 & 4.29 & 8 & 6 \\
\hline
\end{tabular}

Major and minor elements are given in mass percentages and expressed as oxides; trace elements are given in parts per million.

scatterplot of the PCA and plotted in bivariate graphs of log-ratios of elements. As is shown in the example of Figure 5, excellent group separation is achieved when plotting log-ratios of $\mathrm{K}_{2} \mathrm{O}$ and $\mathrm{Sr}$ with $\mathrm{SiO}_{2}$. The 95\% probability ellipses show no overlap of values. Each cluster is strictly related to one production group as defined by archaeological criteria. This result thus indicates a possible origin of historical significance to these patterns.

\section{Discussion}

The main question that needs to be addressed is which factors can explain these distinct chemical signatures, supported by accurate data on a significant number of samples for each group. As of now, several possible explanations can be hypothesized, which will be further addressed in future research.

The first level of explanation we can readily suggest is a naturally occurring variation within the clayey material 

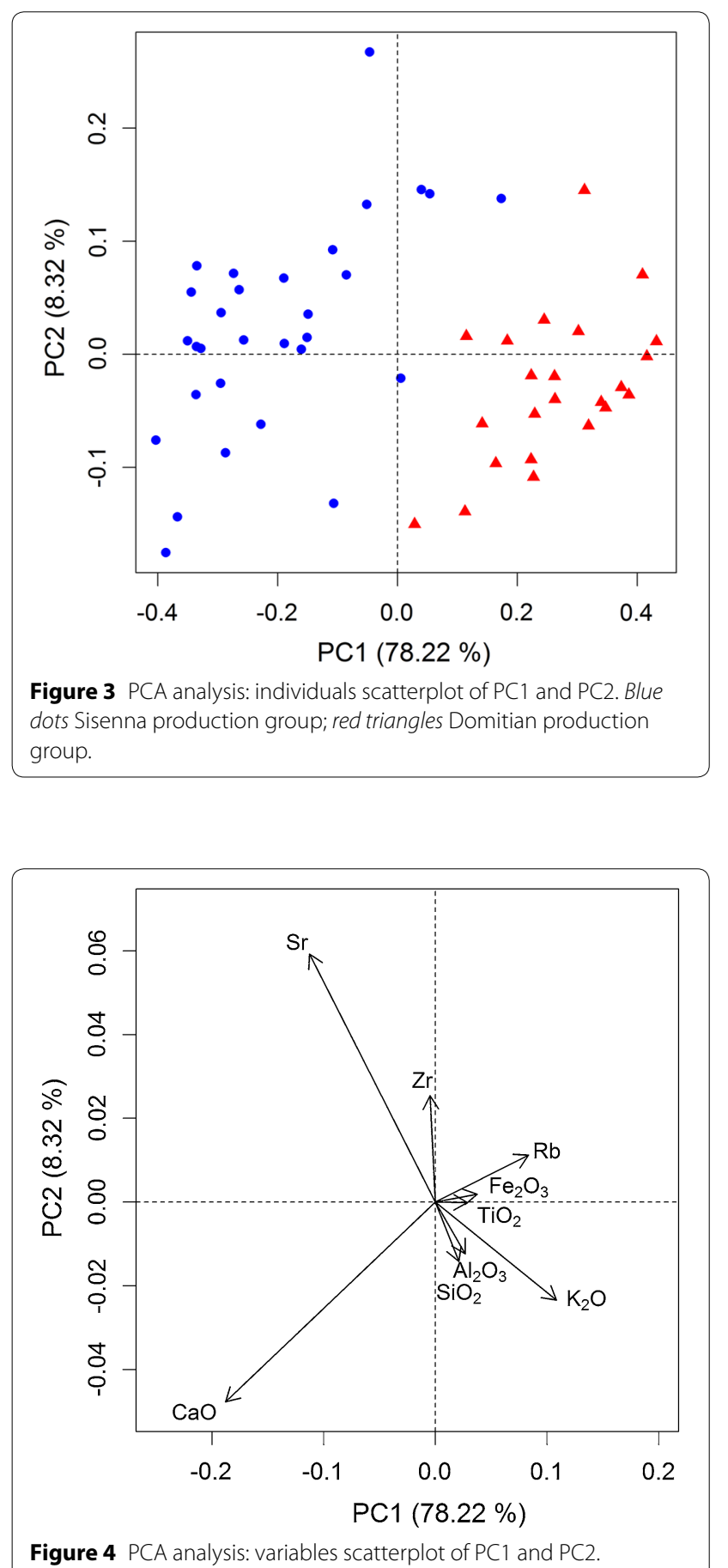

used, whether as a result of the use of two separate clay sources, or due to a high local chemical variation of one single source. Whatever the case, the origin of the raw material would have been discrete, since the two chemical groups are internally quite homogeneous. When examining the geochemical data, what can be noted is the fact that the observed difference does not refer to $\mathrm{SiO}_{2}$

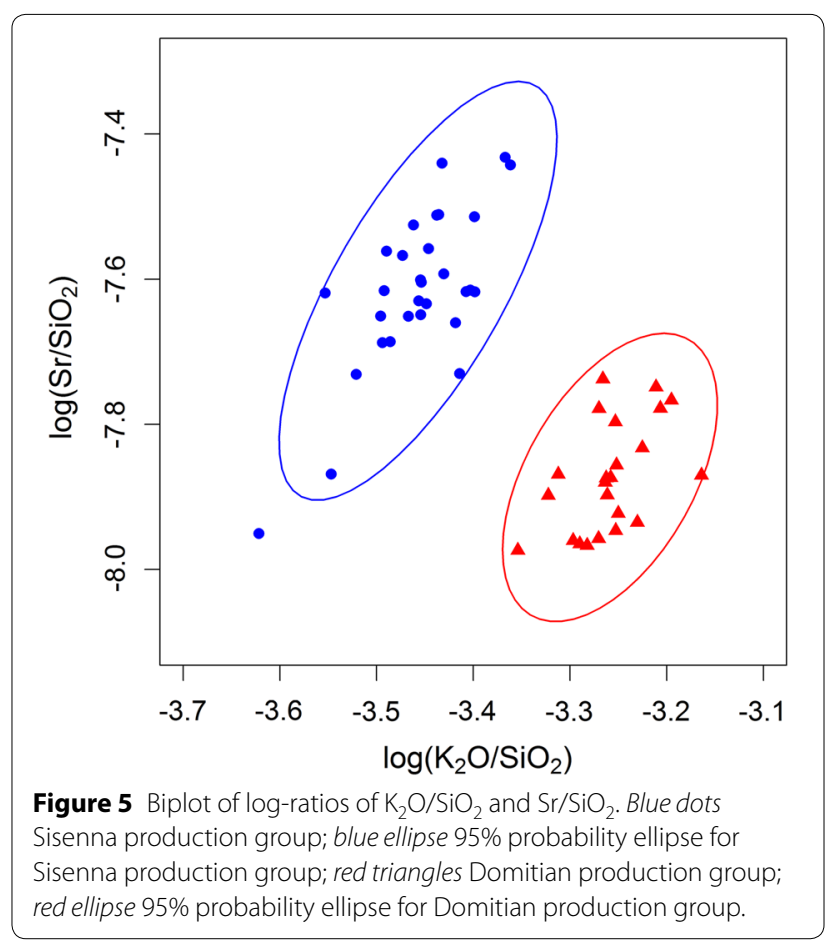

or $\mathrm{Al}_{2} \mathrm{O}_{3}$ contents but mainly to $\mathrm{K}_{2} \mathrm{O}$ and $\mathrm{CaO}$ contents. Depending on whether this difference is related to the elements' presence in the clay matrix or inclusions, we would interpret it differently. For example, different contents of $\mathrm{K}_{2} \mathrm{O}$ in the clay matrix might be associated with a different proportion of illitic clays in the two sources of raw materials used; in inclusions, $\mathrm{K}_{2} \mathrm{O}$ could be related to an abundance of micas or feldspars. Differences in $\mathrm{CaO}$ content might be associated with different natural occurrence of calcareous inclusions, but it could also originate from technological choices made by the ancient potters.

Thus, a second level of explanation relates to the technology of amphora production in the workshop and its evolution through time. Clay bodies are seldom made from a naturally occurring single source of clay sediment. Sometimes quite numerous and complex paste preparation steps are introduced in the chaîne opératoire of the ceramic product. Amphora production is generally regarded as involving minimal paste preparation since the quantities of raw materials needed to ensure a large output would be considerable. Potters are thus supposed to select the most convenient clay material available i.e. one that needs little or no preparation. Nevertheless, this rather simplistic view should not dismiss the fact that addition or removal of non-plastics and clay mixing might have taken place, sometimes in sizeable proportions, which would greatly affect chemical results. This could also explain observed differences in $\mathrm{K}_{2} \mathrm{O}$ and $\mathrm{CaO}$ contents. 
A third level of explanation stems also from human decisions rather than from natural processes, but is related to the larger scale of economic and political spheres. It is possible that the source used at the time of Sisenna was exhausted when Domitian became the owner of the workshop or even that larger social, political or economic factors came into play-for instance, if change of ownership resulted in the availability of a new source of raw material located on imperial land. However, these hypotheses cannot be confirmed by the data so far.

For the moment, none of these explanations can be chosen with certainty above the others. However, this doesn't mean we will not be able to elaborate more solid hypotheses in the future. When every production group will have been sampled and analyzed in the same way (totaling to at least 300 samples in the case of Loron), we will hopefully be able to reconstruct the choices made regarding raw material selection and paste preparation during the whole documented activity of at least three centuries. It will be very interesting to see if comparable patterns emerge, especially for those production groups which lie between Sisenna and Domitian. The present data also need to be supplemented with further methods of analysis, particularly dealing with the mineralogy of ceramic bodies and also by the consideration of raw materials collected in the surrounding area of the workshop.

The recipes chosen by the potters to produce those amphorae are the only remaining trace of numerous factors: choice and preparation of raw materials, the natural availability and variability of those materials, but also how the above varied through more than two centuries of recorded activity, with evidence of changes in ownership and trade of the final product. More specifically, it is interesting to investigate the effects of the shift of ownership from private to imperial status on the organization of production.

Amphorae record every step of their production and use history down to the molecular level. Thus the investigation of chemical signatures is a necessary first step towards addressing questions of fingerprinting, provenance, and technology. The question of provenance of raw materials is certainly not a trivial one in the case of Loron, since the workshop is located in a particular geological context. The Istrian peninsula is composed of Upper Jurassic to Cretaceous carbonate deposits in its southern and western part, and Cretaceous to Paleogene carbonate and clastic sequences, overlain by Eocene foraminiferal limestones, transitional beds and flysch deposits) in its eastern and northeastern part (Figure 2). Karstic and weathering processes during the Neogene and the Quaternary have resulted in the formation of different types of sediments and soils. The most noteworthy of these is terra rossa, a red soil of low calcium content, typical of the Mediterranean climate, found either in karst depressions or as discontinuous surface layers overlying the carbonate plain of southern and western Istria (called quite evocatively "Red Istria") [3, 4]. The Loron workshop is located in this part of the peninsula and its immediate surroundings abound with terra rossa soils but lack other types of clayey sediments, especially calcareous ones, which would be compatible with the ceramic production identified in the workshop. Access to raw materials would therefore have presented a major issue for ancient potters, especially because significant quantities would have been needed to support large scale production. A similar situation is observed at Fažana, in the southern part of the peninsula. Maria Mange and Tamás Bezeczky have conducted a study of the Fažana amphorae, based on heavy minerals, which suggests that terra rossa might have been used in the production of these containers [5].

\section{Conclusions}

The results so far are indeed very promising, considering the scope of the planned study. The ability to discriminate statistically two chemical groups relative to the chronology of production in the workshop is indeed a proof of concept for the capacity of such data to provide exploitable results even at this scale.

Only about half a century or less may separate those two productions, which taken separately are fairly homogeneous regarding a time span of around 20 years in the case of Sisenna, and 13-15 years in the case of Domitian $[2,6]$. Therefore there exists the possibility of defining not only a generic reference group for the whole workshop, but also to establish reference groups for each period of activity in the workshop, which could then be compared to known signatures of other workshops in the same region. Moreover, these groups with high temporal resolution could provide a way to securely identify unstamped amphorae (which make up the major part of ceramic finds), and compare to similar productions in other workshops, as for instance in Fažana, which produces vessels of a similar morphology, but most likely of different chemical composition.

Of course, significant interpretations will only be drawn from the assessment of all the available data. Epigraphy, for example, has demonstrated the growth of the imperial domain at Loron, which could explain-at least partially-why a new source of raw material was exploited at this particular time in the history of the workshop. The merit of adding analytical techniques to the arsenal of traditional archaeological methods is to open new avenues of inquiry. This appears, indeed, to be the case here, 
with the examination of raw material collection and paste preparation steps in ceramic production, which are not commonly studied due to the scarcity of archaeological evidence.

\section{Methods}

\section{Sampling and preparation}

Sampling was performed at the archaeological repository on stamped amphora rims, ensuring each sample was taken from a different vessel. A total of 53 samples were collected, 30 for the Sisenna production group and 23 for the Domitian production group. Subsampling in the laboratory of at least $2 \mathrm{~g}$ of material for chemical analysis was needed in order to ensure representativeness. Surface contaminants were removed mechanically and organic contaminants and adsorbed pore water were removed through calcination at $950^{\circ} \mathrm{C}$ during $1 \mathrm{~h}$. Grinding was performed using a Retsch $\mathrm{S} 100$ tungsten carbide mill (400 rpm, $5 \mathrm{~min}) .13 \mathrm{~mm}$ wide pressed pellets of $200 \mathrm{mg}$ of homogenized sample were obtained with 24,000 lbs applied pressure for $30 \mathrm{~s}$ in a Carver 4,350 L press without the use of binder. This protocol ensured complete reproducibility of results through consistent and minimal preparation steps (and thus minimal contamination due to preparation).

\section{X-ray fluorescence analysis}

Analysis was performed using a Seiko SEA 6000VX EDXRF spectrometer, operating with a $50 \mathrm{kV}$ high voltage, $1 \mathrm{~mA}$ current rhodium X-ray tube and a $50 \mathrm{~mm}^{2}$ silicon drift detector with $155 \mathrm{eV}$ resolution at $5.9 \mathrm{keV}\left(\mathrm{Mn} \mathrm{K}_{\alpha}\right.$ peak). The software employed for instrument operation and spectrum recording and subsequent quantification was the proprietary X-Ray Station (version 10.06.3.0) associated with the instrument. Element intensities were collected for $900 \mathrm{~s}$ (300 s at $15 \mathrm{kV}$ under He flux; $300 \mathrm{~s}$ at $50 \mathrm{kV}$ with a Pb filter; $300 \mathrm{~s}$ at $15 \mathrm{kV}$ with a Cr filter) for each measurement for the following major and minor (expressed as oxides) and trace elements: $\mathrm{Al}_{2} \mathrm{O}_{3}, \mathrm{SiO}_{2}$, $\mathrm{K}_{2} \mathrm{O}, \mathrm{CaO}, \mathrm{TiO}_{2}, \mathrm{Fe}_{2} \mathrm{O}_{3}$ (as total $\mathrm{Fe}$ ), $\mathrm{Rb}, \mathrm{Sr}$, $\mathrm{Zr}$; results were normalized to $100 \%$. The area of analysis was a $3 \mathrm{~mm}$ wide square, ensuring the surface of the pressed pellets appeared perfectly homogeneous and was horizontal in reference to the spectrometer. Quantification was carried out using a fundamental parameters method corrected with the use of an international standard (USGS W-2a) [7]. The detection limits, as determined on the geological standard W-2a, were as follows: $\mathrm{Al}=43 \mathrm{ppm}$, $\mathrm{Si}=24 \mathrm{ppm}, \mathrm{K}=8 \mathrm{ppm}, \mathrm{Ca}=10 \mathrm{ppm}, \mathrm{Ti}=7 \mathrm{ppm}$, $\mathrm{Fe}=6 \mathrm{ppm}, \mathrm{Rb}=1 \mathrm{ppm}, \mathrm{Sr}=1 \mathrm{ppm}, \mathrm{Zr}=1 \mathrm{ppm}$.

\section{Data analysis}

Results of EDXRF analysis are compositional in nature. Owing to this fact, it is necessary to perform one or several data transformations in order to project them in Euclidean space, used by most multivariate statistical methods.

Aitchison proposed in 1986 two different transformations, which have been used in the context of this study [8]. Centered log-ratio transformation (clr) has been performed prior to exploratory principal component analysis (PCA). It is described by Eq. 1 [8]:

$$
\operatorname{cl}(x)=\left[\ln \left(\frac{x_{1}}{g(x)}\right), \ln \left(\frac{x_{2}}{g(x)}\right), \ldots, \ln \left(\frac{x_{D}}{g(x)}\right)\right]
$$

where $g(x)$ is the geometric mean of a $D$ parts composition.

This preliminary step enabled us to select appropriate discriminating chemical elements which have subsequently been plotted in bivariate plots after transformation by the additive log-ratio method (alr). This second type of transformation is explained by Eq. 2 [8]:

$$
\operatorname{alr}(x)=\left[\ln \left(\frac{x_{1}}{x_{D}}\right), \ln \left(\frac{x_{2}}{x_{D}}\right), \ldots, \ln \left(\frac{x_{D-1}}{x_{D}}\right)\right]
$$

All data treatments and analyses have been performed with the $R$ software (version 3.1.0) and the compositions (version 1.40-1), FactoMineR (version 1.27) and car (version 2.0-21) packages [9-12].

\section{Authors' contributions}

PM performed sampling, preparation of samples and analytical work and drafted the manuscript. YM and FT contributed to sampling of materials and provided historical and archaeological context to the study. NC, FXLB, NF and $A B A$ participated in the analytical work and helped with the interpretation of the results. RC oversaw the project and provided support and guidance during the publication process. All authors read and approved the final manuscript.

\section{Author details}

${ }^{1}$ IRAMAT-CRP2A, UMR 5060 CNRS, Université Bordeaux Montaigne, Pessac, France. ${ }^{2}$ AUSONIUS, UMR 5607 CNRS, Université Bordeaux Montaigne, Pessac, France.

\section{Acknowledgements}

This work was funded by the LaScArBx cluster of excellence (programme supported by the Agence Nationale de la Recherche-ANR-10-LABX-52). The Aquitaine region contributed to the acquisition of the EDXRF equipment. We would especially like to thank Brigitte Spiteri for sample preparation and Yannick Lefrais for technical support with EDXRF.

\section{Compliance with ethical guidelines}

\section{Competing interests}

The authors declare that they have no competing interests.

Received: 27 November 2014 Accepted: 19 June 2015

Published online: 03 July 2015 


\section{References}

1. Pollard AM, Heron C (1996) Archaeological chemistry. The Royal Society of Chemistry, Cambridge

2. Tassaux F, Matijašič R, Kovačić $V$ (eds) (2001) Loron (Croatie), un grand centre de production d'amphores à huile istriennes (I ${ }^{\mathrm{er}}$-IV s. P.C.). Ausonius Éditions, Bordeaux

3. Durn G (2003) Terra Rossa in the Mediterranean Region: parent materials, composition and origin. Geologia Croatica 56:83-100

4. Polšak A, Šikić D, Grimani I, Šušnjar M, Mamužić P, Milan A et al (1963) Osnovna Geološka Karta 1:100 000 L33-100 Rovinj. Izradio Institut za geološka istraživanja, Zagreb

5. Mange MA, Bezeczky T (2006) Petrography and provenance of Laecanius Amphorae from Istria, northern Adriatic region, Croatia. Geoarchaeology 21(5):429-460

6. D'Incà C, Kovačić V, Marchiori A, Marion Y, Rousse C, Tassaux F et al (2008) Loron-Lorun, Parenzo-Poreč, Istria. Una villa maritima nell'agro parentino: la campagna di ricerca. Histria Antiqua 2009(17):269-283
7. Govindaraju K (1994) 1994 Compilation of working values and sample description for 383 geostandards. Geostand Newslett 18(Special Issue):16

8. Aitchison J (1986) The statistical analysis of compositional data. Chapman and Hall, New York

9. R Core Team (2014) A Language and environment for statistical computing. R Foundation for Statistical Computing, Vienna

10. van den Boogaart KG, Tolosana-Delgado R (2013) Analyzing compositional data with R. Springer, Berlin, Heidelberg

11. Lê S, Josse J, Husson F (2008) FactoMineR: an R package for multivariate analysis. J Stat Softw 25(1):1-18

12. Fox J, Weisberg S (2011) An R companion to applied regression, 2nd edn. Sage, Thousand Oaks

\section{Publish with ChemistryCentral and every scientist can read your work free of charge}

"Open access provides opportunities to our colleagues in other parts of the globe, by allowing anyone to view the content free of charge."

W. Jeffery Hurst, The Hershey Company.

- available free of charge to the entire scientific community

- peer reviewed and published immediately upon acceptance

- cited in PubMed and archived on PubMed Central

- yours - you keep the copyright

Submit your manuscript here:<smiles>c1ccccc1</smiles>

http://www.chemistrycentral.com/manuscript/ 